\title{
Measuring Fine-Scale White-Tailed Deer Movements and Environmental Influences Using GPS Collars
}

\author{
Stephen L. Webb, ${ }^{1,2}$ Kenneth L. Gee, ${ }^{3}$ Bronson K. Strickland, ${ }^{1}$ Stephen Demarais, ${ }^{1}$ \\ and Randy W. DeYoung 4 \\ ${ }^{1}$ Department of Wildlife, Fisheries and Aquaculture, Mississippi State University, Box 9690, Mississippi State, MS 39762, USA \\ ${ }^{2}$ Hayden-Wing Associates, 2308 S. 8th St., Laramie, WY 82070, USA \\ ${ }^{3}$ Samuel Roberts Noble Foundation, 2510 Sam Noble Parkway, Ardmore, OK 73401, USA \\ ${ }^{4}$ Caesar Kleberg Wildlife Research Institute, Texas A\&M University-Kingsville, 700 University Blvd., MSC 218, Kingsville, \\ TX 78363, USA
}

Correspondence should be addressed to Stephen L. Webb, stephenwebb@hotmail.com

Received 17 April 2009; Accepted 17 January 2010

Academic Editor: Lyn Branch

Copyright (C) 2010 Stephen L. Webb et al. This is an open access article distributed under the Creative Commons Attribution License, which permits unrestricted use, distribution, and reproduction in any medium, provided the original work is properly cited.

\begin{abstract}
Few studies have documented fine-scale movements of ungulate species, including white-tailed deer (Odocoileus virginianus), despite the advent of global positioning system (GPS) technology incorporated into tracking devices. We collected fine-scale temporal location estimates (i.e., $15 \mathrm{~min} /$ relocation attempt) from 17 female and 15 male white-tailed deer over 7 years and 3 seasons in Oklahoma, USA. Our objectives were to document fine-scale movements of females and males and determine effects of reproductive phase, moon phase, and short-term weather patterns on movements. Female and male movements were primarily crepuscular. Male total daily movements were $20 \%$ greater during rut $(7,363 \mathrm{~m} \pm 364)$ than postrut $(6,156 \mathrm{~m} \pm 260)$. Female daily movements were greatest during postparturition $(3,357 \mathrm{~m} \pm 91)$, followed by parturition $(2,902 \mathrm{~m} \pm 107)$, and preparturition $(2,682 \mathrm{~m} \pm 121)$. We found moon phase had no effect on daily, nocturnal, and diurnal deer movements and fine-scale temporal weather conditions had an inconsistent influence on deer movement patterns within season. Our data suggest that hourly and daily variation in weather events have minimal impact on movements of white-tailed deer in southern latitudes. Instead, routine crepuscular movements, presumed to maximize thermoregulation and minimize predation risk, appear to be the most important factors influencing movements.
\end{abstract}

\section{Introduction}

White-tailed deer (Odocoileus virginianus) movement studies have focused on movements of white-tailed deer at varying spatial scales, from large-scale dispersal and migration to small-scale movements within home ranges and habitats [1]. However, few studies have documented fine-scale temporal movements (i.e., movement distance calculated $<1$ hour) of ungulate species [2], including white-tailed deer, despite the advent of global positioning system (GPS) collars.

A number of factors influence deer movements including physiology, which includes breeding and parturition, general changes in season and daylength, and environmental influences such as weather. Reproductive phase influences spatial ecology of both sexes. Females alter home range size, mobility, and social interactions [1,3-5]. For instance, home range size of females was smaller during parturition subperiods (14 May-14 July) than during spring, possibly because of changes in movement patterns [1]. Studies conducted in both captive $[3,4]$ and free-ranging populations [5-7] have reported similar reductions in female home range size during parturition. Males increase home range size during rut, presumably to search for receptive females [8]. However, Webb et al. [1] reported no change in home range size but documented more linear movement patterns. Further information is needed to determine if more linear movements are the result of a general change in movement pattern, without a change in movement distance, or because of increased movement distances. 
Deer activity relative to environmental factors has been evaluated across the northern U.S. [9-14]. Less extensive studies examined broad-scale temporal relationships of white-tailed deer activity and movement patterns to environmental conditions in the southern U.S. [15-19]. Thus, information on fine-scale temporal responses to environmental variables is largely restricted to the northern portion of the species' range. Winter weather conditions are not as severe in southern climates compared to snow laden northern climates [20]. However, high temperatures during summer may exert greater influences on deer movement patterns in southern climates. By correlating short-term weather phenomena with fine-scale deer movements we hope to gain insight into the effect of weather on deer movements.

The effect of moon phase on white-tailed deer has received much attention in popular literature [21]. Some scientific studies of moon phase and deer activity have used visual observations $[12,15,22]$, which could have been affected by visibility of the deer and human disturbance. Several other studies $[14,23,24]$ used radio telemetry to relate activity rates or movements to moon phase with varied results. Studies quantifying animal activity or movement are few; thus, more data are needed to test effects of moon phase on deer movements.

Using fine-scale temporal data (i.e., $15 \mathrm{~min} /$ relocation), we documented the effects of reproductive phase, weather, and moon phase on deer movements at a temporal scale not previously reported for white-tailed deer. Our objectives were to (1) document and compare fine-scale temporal movements of females during parturition and males during rut, (2) determine the effects of moon phase on deer movements, and (3) determine the effects of short-term weather patterns on deer movements. Because our main objective was to document fine-scale movements of deer as accurately as possible we used a short sampling interval [25]. We hypothesized that females and males would show similar trends in movement patterns during spring because both sexes would be concentrating on foraging to meet metabolic requirements for fawn production and antler growth, respectively. We hypothesized that movements of females during summer would decrease because of parturition and care of young and movement of males during winter would increase because of searching behaviors associated with breeding. Last, we hypothesized that moon phase and weather would have relatively little influence on deer movements because seasonal weather conditions are less severe in southern latitudes.

\section{Methods}

2.1. Study Area. We conducted our study on the Samuel Roberts Noble Foundation Wildlife Unit (NFWU) located in southern Oklahoma in Coal, Hughes, and Pontotoc Counties (Figure 1). The NFWU is 1,214 ha in size and is $8.0 \mathrm{~km}$ south of Allen, Oklahoma in the Cross Timbers and Prairies ecoregion. A $2.5-\mathrm{m}$ tall, high-tensile electric fence (HTEF) containing 15 smooth wire strands with alternating positive and negative wires was erected around 1,184 ha of the study area. The HTEF was not a complete barrier to

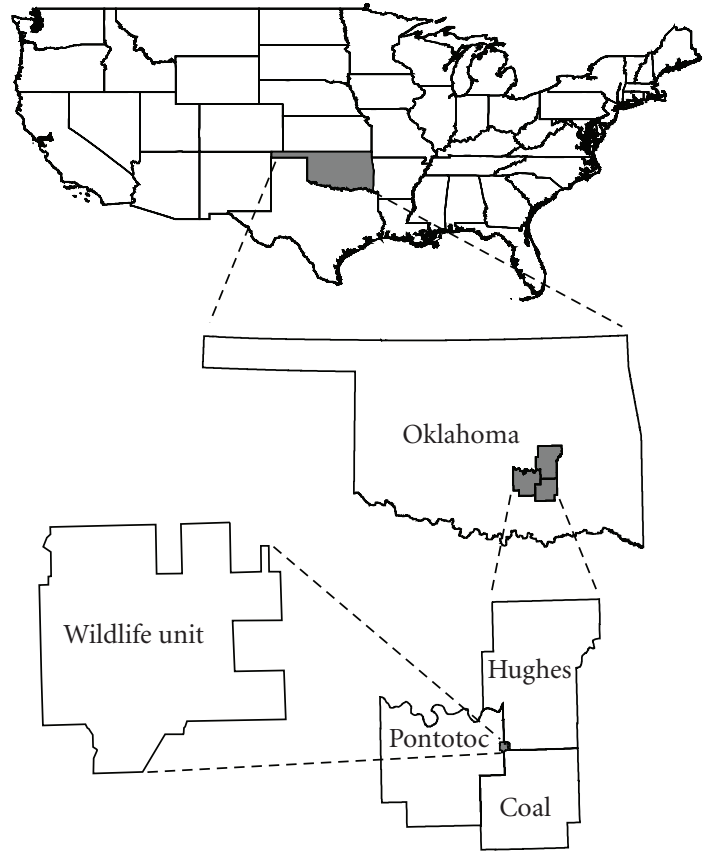

FIgUre 1: Samuel Roberts Noble Foundation Wildlife Unit located in Coal, Hughes, and Pontotoc Counties, Oklahoma, USA.

deer movements. Tagging and GPS collar studies found deer passed through the fence and home ranges and movements were minimally affected by its presence $[1,26]$. The NFWU is approximately $60 \%$ wooded and $40 \%$ open, with a high degree of interspersion [27]. During years when collars were operational, rainfall ranged from 64.8 to $117.6 \mathrm{~cm}$ (Ada, OK [28]). Average January temperature was $4.8^{\circ} \mathrm{C}$ and average July temperature was $27.7^{\circ} \mathrm{C}$ during the study (Ada, OK [28]). Hunting pressure was light to moderate, primarily for females to control population numbers whereas harvest of males was restricted to individuals $\geq 3.5$ years. Trends in population estimates revealed that the population was increasing during the study with the last 2 years having the highest estimates ( 1 deer/7.2 ha). Population estimates ranged from 1 deer/18.5 ha to 1 deer/7.2 ha (K. L. Gee, unpublished data).

2.2. Capture and Handling. We captured deer using a dropnet $[29,30]$ baited with corn during winter and a tranquilizer dartgun (Pneu-Dart, Inc., Williamsport, PA, USA) during fall. We sedated deer using Xylazine $(3-6 \mathrm{mg} / \mathrm{kg}$, Phoenix Scientific, St. Joseph, Missouri, USA) or a Telazol-Xylazine mixture $(4.4 \mathrm{mg} / \mathrm{kg}$ Telazol, Fort Dodge Animal Health, Fort Dodge, IA, USA, plus $2.2 \mathrm{mg} / \mathrm{kg}$ xylazine) and used yohimbine (Abbott Laboratories, North Chicago, IL, USA) at $0.125 \mathrm{mg} / \mathrm{kg}$ or tolazine at $0.4 \mathrm{mg} / \mathrm{kg}$ as an antagonist to the xylazine. We captured 38 (21 females, 17 males) adult deer ( $\geq 1.5$ years) during autumn over 7 years; 5 (4F, $1 \mathrm{M})$ in $1998,2(1 \mathrm{~F}, 1 \mathrm{M})$ in $1999,5(3 \mathrm{~F}, 2 \mathrm{M})$ in $2000,5(2 \mathrm{~F}, 3 \mathrm{M})$ in $2001,10(4 \mathrm{~F}, 6 \mathrm{M})$ in $2002,8(7 \mathrm{~F}, 1 \mathrm{M})$ in 2003 , and 3 (0F, $3 \mathrm{M})$ in 2004. Deer were fitted with a G2000 remote-release global positioning system (GPS) collar (Advanced Telemetry Systems, Isanti, MN, USA) and plastic livestock ear tags. 
We excluded data from 6 deer because of collar malfunctions (3), short tracking periods of $<7$ days (1), and small sample size for females during winter (1) and males during summer (1). Thus, we analyzed data on 32 of 38 ( 9 females and 9 males during spring, 8 females during summer, and 6 males during winter) deer for a total of 130,098 GPS locations. On average, collars collected 4,065 locations $( \pm 354)$ for an average of 54 days $( \pm 3)$. Average age of females at time of data collection was $3.6( \pm 0.3)$ and $3.6( \pm 0.4)$ for males. Only 1 deer, a male, was $<2$ years at time of data collection.

\subsection{Data Collection}

2.3.1. GPS Location Fixes. We programmed GPS collars to begin collecting data during 1 of 3 seasons: spring (MarchMay; $n=20 ; 10 \mathrm{~F}, 10 \mathrm{M}$ ), summer (June-August; $n=11$; $10 \mathrm{~F}, 1 \mathrm{M}$ ), and winter (November-February; $n=7 ; 1 \mathrm{~F}, 6 \mathrm{M}$ ). A GPS fix was attempted every 15 minutes for 60-75 days, which would result in 4 fixes/hr. At our fix schedule, memory was exceeded before the end of battery life. No individual deer provided data during an entire season because memory capacity of the collar was exceeded. Hereafter, we refer to the distance moved between 2 fixes as a movement. Four movements are possible/hr by using all fixes within an hour and the first fix of the following hour. We remotely triggered release of collars after approximately 4 months and downloaded location estimates.

2.3.2. Moon Phase. We used proportion of the moon's surface illuminated, which is a quantitative measure of the moon's appearance, as a surrogate for moon phase similar to Beier and McCullough [14]. Percentage illumination is calculated as area illuminated divided by total moon area multiplied by 100 . We did not differentiate between waxing and waning crescent or gibbous phases or between first and last quarters. We also did not account for cloud cover because we were only interested in documenting movements relative to moon phase and not moon visibility. We classified moon phase as new $(0.0-0.05)$, crescent $(0.2-0.3)$, quarter (0.45-0.55), gibbous (0.7-0.8), and full (0.95-1.0). If moon phase did not fall into one of the aforementioned phases then it was grouped into an "other" category and also was included into our analyses. Astronomical data were downloaded from the United States Naval Observatory website (http://www.usno.navy.mil/USNO) for Allen, Oklahoma ( $8 \mathrm{~km}$ south of the NFWU).

2.3.3. Weather Conditions. We obtained weather data from the Oklahoma Mesonet system, a network of environmental monitoring stations (http://www.mesonet.org/). The network consists of over 110 automated stations with at least one station in each of Oklahoma's 77 counties. Environmental conditions, measured every 5 minutes, are recorded at the Oklahoma Climatological Survey. We obtained mean hourly estimates of 5 weather variables from the Centrahoma reporting station, which was located $18.0 \mathrm{~km}$ southsoutheast of our study area. The variables we collected were air temperature $\left({ }^{\circ} \mathrm{C}\right)$, wind speed $(\mathrm{m} / \mathrm{sec} ; 1 \mathrm{~m} / \mathrm{sec}=$ $3.6 \mathrm{~km} / \mathrm{hr}$ ), pressure (millibars), relative humidity (\%), and total precipitation $(\mathrm{mn} ; 10 \mathrm{mn}=1 \mathrm{~cm})$.

\subsection{Analysis}

2.4.1. Hourly Movements. We determined total hourly distance travelled by adding straight-line distances between successive fixes for individual deer. We calculated a mean distance traveled by hour for each deer and used these means to calculate an overall mean of hourly movements by sex and season. Because of the short-time interval, we only used deer with all 4 movements/hr. We used a 2-sample $t$-test, assuming equal variances, to compare hourly movement distance between females and males during spring, females during spring and summer, and males during spring and winter.

2.4.2. Effects of Reproductive Phase. On the study area, mean conception occurred 30 November \pm 1.5 days $(\mathrm{SE}$; range $=$ 4 November-24 December) and mean parturition occurred 15 June \pm 1.5 days (SE; range $=23$ May-12 July; [1]). To avoid the influence of very early or late conceptions on mean conception date, we defined reproductive seasons according to the frequency of conceptions by week. We divided parturition into 3 subperiods similar to Webb et al. [1]: preparturition (14 May-7 June), parturition (8 June22 June) and postparturition (23 June-14 July). Based on conception dates the rut was partitioned into 2 subperiods: rut (18 November-1 December) and postrut (2 December23 December). No males were tracked prior to the beginning of the rut sub-period.

To evaluate differences in total daily deer movement by reproductive sub-period, we used a repeated measures design (PROC MIXED [31]) with day as a repeated measure and deer as subject, which specifies the unit within which observations are correlated [32]. We selected our covariance structure using restricted maximum likelihood and Akaike information criterion corrected for sample size (AICc [33]). Based on model results, we used a first order autoregressive covariance structure for females and a compound symmetry covariance structure for males.

2.4.3. Diurnal/Nocturnal Movements. We downloaded sunrise and sunset data for Allen, Oklahoma $(8 \mathrm{~km}$ south of the NFWU) from the United States Naval Observatory website (http://www.usno.navy.mil/USNO) to determine diurnal and nocturnal movements. Diurnal hours were calculated as the hour of sunrise to the hour of sunset and nocturnal hours as the next hour after sunset and the last hour before sunrise. Deer with $\geq 2$ movements/hr within time period were used in these analyses. A diurnal : nocturnal movement ratio ( $\mathrm{D}: \mathrm{N}$ [34]) also was calculated from movement rates within diurnal and nocturnal periods. Diurnal: nocturnal ratios $<1$ indicate greater nocturnal movements and $\mathrm{D}: \mathrm{N}>1$ indicates greater diurnal movements. Movement rates were used to calculate $\mathrm{D}: \mathrm{N}$ ratios instead of movement distance to account for variations in daylength.

2.4.4. Moon Phase. To test for effects of moon phase, time period (i.e., diurnal and nocturnal) and moon phase $\times$ time period interaction on sex and seasonal deer movement 
rates (response variable), we ran a 2-way repeated measures ANOVA (PROC MIXED [31]) with moon phase as a repeated measure and deer as subject. Movement rate was the metric used in our ANOVA because of unequal hours within time period. We used a compound symmetry covariance structure.

2.4.5. Weather. To determine the effect of weather conditions on deer movement patterns within their normal activity rhythms, we totaled the distance moved within each of 43 hr time periods using only deer with all 12 movements/time period. Analyzing data during each 3-hr time period allowed us to relate deer movements to actual weather during that time period. Morning movement period was defined as movement during the hours of 0600-0859 hours for females during spring and summer and for males during spring and from 0700-0959 hours for males during winter. Midday movement period was 1200-1459 hours for females and males during all seasons. Evening movement period was defined as 1700-1959 hours for females during spring and males during spring and winter, and 1900-2159 hours for females during summer. Midnight movement period was from 0000-0259 hours for females during spring and males during spring and winter, and 0100-0359 hours for females during summer.

To assess whether each weather variable was related to movements, we used general linear models with repeated measures (PROC MIXED [31]) to calculate parameter estimates by sex, season, and time period with day as a repeated measure and deer as subject. We used a spatial power covariance structure for our models.

Despite having sufficient sample size and power to detect general linear relationships, we also considered potential nonlinear effects extreme weather conditions may have on deer movements. We calculated $z$-scores (PROC STANDARD [31]) based on standard deviations from the mean for each of the 5 independent weather variables during times specified for each sex, season, and time period. We used a repeated measures ANOVA (PROC MIXED [31]) with time period (i.e., morning, midday, evening, or night) as a repeated measure and deer as subject to compare movement rates of deer during periods of extreme weather (i.e., low and high) and normal weather. We compared deer movements that occurred when weather conditions were $\geq 1$ SD above the mean, $\leq 1$ SD below the mean, and between the 2 extremes (i.e., -1 to 1 ) for each weather variable. Assuming normal distributions of weather variables, $68 \%$ of observations would fall within \pm 1 SD of the mean leaving $16 \%$ of observations above and below 1 SD of the mean, respectively. Data were analyzed by sex, season, and time period. Because precipitation did not deviate below $1 \mathrm{SD}$ from the mean, we compared movements during extreme highs in precipitation to movements during periods of no precipitation. We used a compound symmetry covariance structure for our models. When a significant $F$-test occurred, we used Tukey's mean comparison test to compare among weather conditions.

To determine if diel changes in weather conditions influenced movement patterns we calculated differences in weather conditions from 1 day to the next within the middle hour for each of the 4 aforementioned movement periods. We used a repeated measures ANOVA (PROC MIXED [31]) with hour as a repeated measure and deer as subject to compare movement distances of deer among 7 equidistant categories relating to changes in pressure (-10.4--7.2; $-7.2--4.0 ;-4.0--0.8 ;-0.8-2.4 ; 2.4-5.6 ; 5.6-8.8 ; 8.8-$ 12.3), precipitation $(-13.8--9.9 ;-9.9--6.0 ;-6.0--2.1$; $-2.1-1.8 ; 1.8-5.7 ; 5.7-9.6 ; 9.6-13.8)$, temperature $(-10.2-$ $-7.6 ;-7.6--5.0 ;-5.0--2.4 ;-2.4-0.2 ; 0.2-2.8 ; 2.8-5.4$; $5.4-8.1)$, wind speed $(-2.8--2 ;-2--1.2 ;-1.2--0.4 ;-0.4-$ $0.4 ; 0.4-1.2 ; 1.2-2.0 ; 2.0-2.8)$, and relative humidity $(-25.3-$ $-18.1 ;-18.1--10.9 ;-10.9--3.7$; -3.7-3.5; 3.5-10.7; $10.7-$ $17.9 ; 17.9-25.1)$. Data were analyzed by sex, season, and hour to account for sex, season, and hour specific movements while using a compound symmetry covariance structure for our models.

All statistical analyses were conducted using SAS 9.1 [31]. We used an a priori $\alpha=0.05$ for statistical tests. All means are reported with standard error $( \pm S E)$ unless otherwise noted. For all repeated measures designs and mixed models, we used a degrees of freedom adjustment developed by Kenward and Roger [35]. The Kenward-Roger option accounts for unbalanced data, multiple random effects, and any model with correlated errors [32]. We examined plots of residuals and normal probability plots to evaluate normality assumptions.

\section{Results}

Mean number of movements/day was $79 \pm 0.3$ (95\% CI: 78.7-80.1), which was within $95 \%$ of total distance travelled if all 96 movements were used. Deer with 4859 movements/day accounted for $<10 \%$ of all observations.

3.1. Hourly Movements. During spring, both sexes exhibited 2 primary peaks in movement from 0600-0800 hours and again from 1700-1900 hours, which closely corresponded with sunrise and sunset (Figures 2(a) and 2(b)). Peaks in movements began at sunrise and 2 hours prior to sunset (Figures 2(a) and 2(b)). Female movements ranged from a low of $177 \mathrm{~m}( \pm 28)$ at 0200 and $177 \mathrm{~m}( \pm 31)$ at 1400 hours to a high of $357 \mathrm{~m}( \pm 38)$ at 0700 hours. Male movements ranged from $169 \mathrm{~m}( \pm 29)$ at 1100 hours to $403 \mathrm{~m}( \pm 23)$ at $1800 \mathrm{hr}$. We found no difference in hourly movement distance between females and males during any hour in spring $(P \geq .15)$.

Peak movements by females during spring were more distinct than during summer. Summer hourly movements were around $150 \mathrm{~m}$ per hr (Figure 3(a)). Movements increased after sunrise with peak movements occurring at 1200 hours $(210 \mathrm{~m} \pm 48)$ and just before sunset with another peak at 2000 hours $(210 \mathrm{~m} \pm 36)$ whereas movement was lowest at 0300 hours $(95 \mathrm{~m} \pm 12$; Figure 3(a)). Female movements during spring exceeded movements during summer $50 \%$ of the time and were similar the other $50 \%$ of the time. Movements during spring were greater at 0200-0300, 0500-0800, 1100, 1300, and 1600-1900 hours $(P \leq .03)$. 


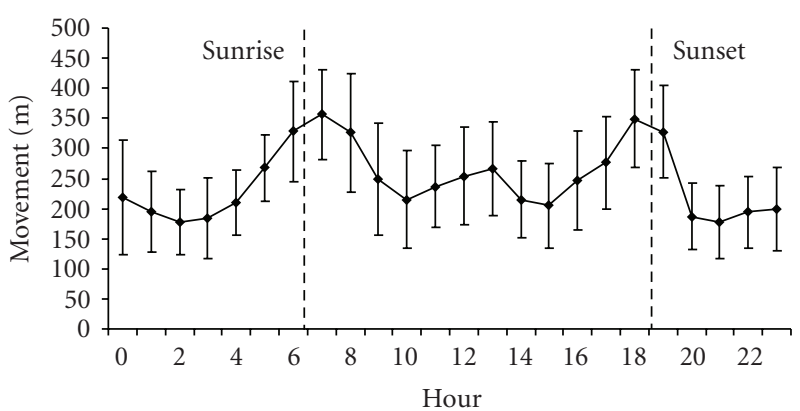

(a)

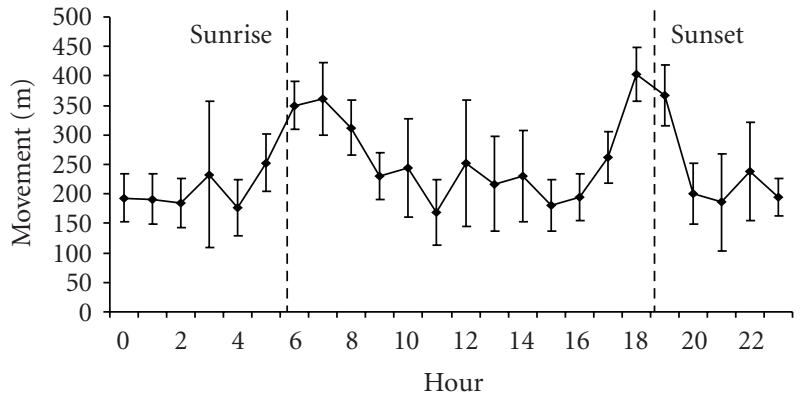

(b)

Figure 2: Mean hourly movements (m) of female (a) and male (b) white-tailed deer during spring (March-May).

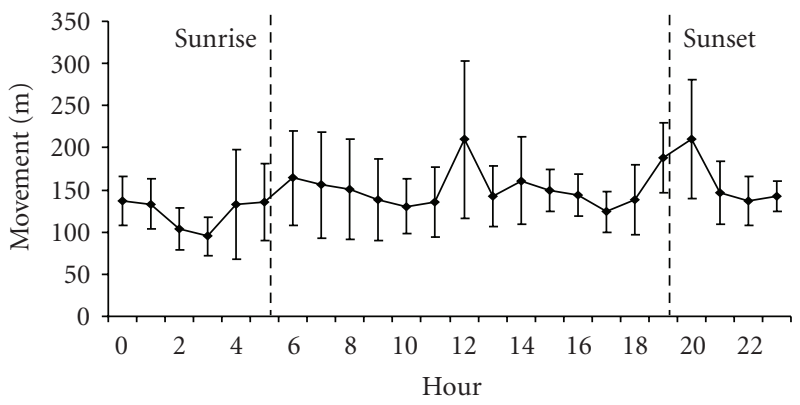

(a)



(b)

FIGURE 3: Mean hourly movements ( $\mathrm{m}$ ) of female (a) white-tailed deer during summer (June-August) and male (b) white-tailed deer during winter (November-February).

Males in winter predominately moved during 0700-0900 hours and from 1700-1900 hours, immediately after sunrise and sunset, respectively (Figure 3(b)). Decreased movements occurred from 1200-1500 hours (Figure 3(b)). Movement was greatest at 0700 hours $(436 \mathrm{~m} \pm 55)$ and least at 1200 hours (131 m \pm 1 ; ; Figure 3(b)). We found male movement distance differed from spring and winter for 5 of 24 hours. Males moved greater distances from $0500-0600 \mathrm{hr}$ and 1900 hours during spring compared to winter $(P \leq .04)$. At 0900 and 1700 hours male movements were greater during winter than spring $(P \leq .05)$.

3.2. Effects of Reproductive Phase. Female daily movements varied by parturition sub-period $\left(F_{2,63.3}=3.35, P=\right.$ $.04)$. Female daily movements were lowest during preparturition (2,682 $\mathrm{m} \pm 121$; 95\% CI: 2,438-2,926) followed by parturition (2,902 $\mathrm{m} \pm 107$; $95 \% \mathrm{CI}: 2,690-3,114)$. Female daily movements during post-parturition $(3,357 \mathrm{~m} \pm 91$; 95\% CI: $3,176-3,538)$ were $25 \%$ and $16 \%$ greater than pre-parturition and parturition, respectively. Movements among females also were less variable during parturition subperiods; therefore, females appeared to respond similarly to parturition.

Male daily movements did not differ between rut and postrut $\left(F_{1,144}=3.33, P=.07\right)$. However, daily movements during rut $(7,363 \mathrm{~m} \pm 364 ; 95 \%$ CI: 6,633-8,093) were $20 \%$ greater than during postrut $(6,156 \mathrm{~m} \pm 260 ; 95 \% \mathrm{CI}$ :
5,639-6,673), which represents a rather large increase in movements over a short period of time. Male movements also were more variable during the rut, which may indicate different search patterns for receptive females.

3.3. Moon Phase. Moon phase had no influence on movement rates $(P \geq .15)$ or the interaction between time period and moon phase $(P \geq .25)$. Female movement rates during spring $\left(F_{1,699}=13.74, P<.01\right)$ and summer $\left(F_{1,610}=42.39\right.$, $P<.01$; Table 1 ) were influenced by time period (i.e., diurnal and nocturnal). Male movement rate also was influenced by time period during spring $\left(F_{1,746}=4.06, P=.04\right)$ and winter $\left(F_{1,684}=10.96, P<.01\right.$; Table 1$)$. After accounting for daylength, female movement rates and male movement rates during winter were greater during nocturnal hours (i.e., $\mathrm{D}: \mathrm{N} \leq 0.98$; Table 1). However, male movement rates during spring were greater during daylight hours ( $\mathrm{D}: \mathrm{N}=1.04$; Table 1).

\subsection{Weather}

3.4.1. Linear Relationships. We found general linear trends in movements related to 4 of the 5 weather variables in only 8 of 80 (10\%) models (Table 2). Temperature influenced movements in 5 of 8 cases and rain, relative humidity and wind speed each in 1 case (Table 2). Parameter estimates of the 8 significant models do not provide useful biological 
TABLE 1: Seasonal diurnal and nocturnal hourly movement rates $(m)$ and diurnal: nocturnal movement ratio (D:N) of females and males.

\begin{tabular}{|c|c|c|c|c|c|c|c|}
\hline \multirow{2}{*}{ Sex } & \multirow{2}{*}{ Season } & \multirow{2}{*}{$n$} & \multirow{2}{*}{ Time period } & \multirow{2}{*}{ Mean (SE) } & \multicolumn{2}{|c|}{$95 \% \mathrm{CI}$} & \multirow{2}{*}{$D: N$} \\
\hline & & & & & Lower & Upper & \\
\hline \multirow{4}{*}{ Female } & \multirow{2}{*}{ Spring } & 373 & Nocturnal & $219(6)$ & 207 & 230 & 0.98 \\
\hline & & 348 & Diurnal & $215(6)$ & 204 & 226 & \\
\hline & \multirow{2}{*}{ Summer } & 312 & Nocturnal & $140(3)$ & 134 & 147 & 0.79 \\
\hline & & 313 & Diurnal & $111(2)$ & 106 & 115 & \\
\hline \multirow{4}{*}{ Male } & \multirow{2}{*}{ Spring } & 389 & Nocturnal & $202(4)$ & 193 & 210 & 1.04 \\
\hline & & 377 & Diurnal & $210(4)$ & 202 & 218 & \\
\hline & \multirow{2}{*}{ Winter } & 363 & Nocturnal & $262(7)$ & 248 & 276 & 0.87 \\
\hline & & 341 & Diurnal & $228(7)$ & 214 & 241 & \\
\hline
\end{tabular}

TABLE 2: Linear relationships between weather variables and female and male white-tailed deer movements across seasons and time periods.

\begin{tabular}{|c|c|c|c|c|c|c|c|c|c|}
\hline Sex & Season & Period & Variable & Intercept & Estimate & SE & $\mathrm{df}$ & $F$ & $P$ \\
\hline \multirow{3}{*}{ Female } & \multirow{2}{*}{ Spring } & Morning & Temperature & $1,112.6$ & -14.70 & 7.21 & 136 & 4.15 & .044 \\
\hline & & Night & Precipitation & 613.9 & 87.05 & 38.95 & 351 & 4.99 & .026 \\
\hline & Summer & Evening & Relative humidity & $1,203.6$ & -8.81 & 4.12 & 183 & 4.58 & .034 \\
\hline \multirow{5}{*}{ Male } & \multirow{4}{*}{ Spring } & Evening & Temperature & $1,351.8$ & -20.37 & 5.67 & 141 & 12.91 & $<.001$ \\
\hline & & Midday & Temperature & 820.7 & -17.72 & 5.73 & 124 & 9.57 & .002 \\
\hline & & Morning & Temperature & $1,441.8$ & -39.49 & 6.58 & 137 & 36.03 & $<.001$ \\
\hline & & Morning & Wind speed & $1,228.3$ & -68.44 & 33.36 & 202 & 4.21 & .042 \\
\hline & Winter & Night & Temperature & 673.4 & 13.67 & 6.85 & 167 & 3.98 & .048 \\
\hline
\end{tabular}

meaning as all parameter estimates were $\leq 29 \mathrm{~m} / \mathrm{hr}$, which partially may be related to collar error or tortuosity of movement paths at short time intervals. Overall, no apparent trend $(P \geq .06)$ of weather effects on movements of either sex during any season or time period was observed (Table 2).

3.4.2. Nonlinear Relationships. To assess nonlinear relationships, we categorized weather conditions into 3 classes (lower, normal and upper) based on deviations from normal patterns by sex, season, and time period (Table 3 ). We found differences among movements categories relative to weather conditions in 11 of $80(13.8 \%)$ models (Table 4$)$. Temperature accounted for most ( 6 of $11 ; 55 \%$ ) differences in movements, followed by relative humidity (3), precipitation (1), and wind speed ( 1 ; Table 4). Overall, a general pattern in how weather influenced deer movements was not observed, except that temperature influenced deer movements more than any other weather variable.

3.4.3. Diel Changes. Changes in weather patterns within hour from 1 day to the next affected movements in 10 of 80 models $(12.5 \%)$. Temperature, relative humidity and wind speed each affected movements in 2 instances, whereas precipitation and pressure affected movements in 1 and 3 instances, respectively (Figure 4). Movements were primarily affected during hours of limited movements (i.e., 0100-0200, 1300; Figure 4). Besides weather influencing movements during nonpeak movement periods, no other patterns of weather influences on movements were observed.

\section{Discussion}

We found white-tailed deer movements primarily were crepuscular, which is similar to trends previously reported [14-16]. Although previous studies documented movements were greatest near sunrise and sunset, parameter estimates of movement distance may differ with frequency of relocations. If the purpose is to accurately estimate movement distance, and not just document trends in movement, then the shortest sampling frequency between relocations should be used. We also documented changes in daily movements across seasons, which can reflect physiological changes within the animal or responses to environmental change.

Analysis of data only across long-time periods, such as seasons or years, may mask changes in movement patterns at finer temporal scales (e.g., hours, days, or critical life history phases). Subdividing seasons into biological seasons pertaining to breeding, revealed changes in daily movement patterns. Previous studies found that parturition influenced home range size, movement, and social interactions [1, 3-5]. We also found that reproductive period influenced female movements. Movements were greater during postparturition which may be influenced by increased fawn mobility or increased energy requirements because of demands from lactation. Increased energy demands may require females to move farther between foraging patches. Another analysis of our data showed that female home range size (i.e., extent of space used) was less during parturition compared to spring [1], which is similar to previous research [3-7]. Based on fractal analyses, female movement path tortuosity changed relative to parturition sub-period. 
TABLE 3: Means $( \pm \mathrm{SD})$ of temperature $\left({ }^{\circ} \mathrm{C}\right)$, relative humidity $(\%)$, wind speed $(\mathrm{m} / \mathrm{sec})$, precipitation $(\mathrm{mn})$, and pressure (millibars) during each respective season and time period. Means \pm SD were used to compare movements during extreme weather events.

\begin{tabular}{|c|c|c|c|c|c|c|c|c|}
\hline Sex & Season & Time period & $n$ & $\begin{array}{l}\text { Temperature } \\
\text { Mean } \pm \text { SD }\end{array}$ & $\begin{array}{l}\text { Relative humidity } \\
\text { Mean } \pm \text { SD }\end{array}$ & $\begin{array}{l}\text { Wind speed } \\
\text { Mean } \pm \text { SD }\end{array}$ & $\begin{array}{l}\text { Precipitation } \\
\text { Mean } \pm \text { SD }\end{array}$ & $\begin{array}{c}\text { Pressure } \\
\text { Mean } \pm \mathrm{SD}\end{array}$ \\
\hline \multirow{8}{*}{ Female } & \multirow{5}{*}{ Spring } & Morning & 397 & $10.75 \pm 5.25$ & $81.34 \pm 9.0$ & $3.24 \pm 1.02$ & $0.2 \pm 0.84$ & $992.11 \pm 5.12$ \\
\hline & & Midday & 287 & $18.14 \pm 5.26$ & $56.78 \pm 15.8$ & $4.48 \pm 1.23$ & $0.09 \pm 0.44$ & $990.39 \pm 4.96$ \\
\hline & & Evening & 378 & $16.38 \pm 5.23$ & $61.82 \pm 14.48$ & $3.34 \pm 1.08$ & $0.16 \pm 0.87$ & $989.79 \pm 5.01$ \\
\hline & & Night & 465 & $11.85 \pm 5.53$ & $82.82 \pm 9.07$ & $2.58 \pm 1.25$ & $0.07 \pm 0.41$ & $990.51 \pm 4.93$ \\
\hline & & Morning & 282 & $22.74 \pm 1.87$ & $88.51 \pm 4.31$ & $2.37 \pm 0.95$ & $0.35 \pm 1.22$ & $990.92 \pm 2.51$ \\
\hline & \multirow{3}{*}{ Summer } & Midday & 264 & $28.6 \pm 2.71$ & $64.93 \pm 10.55$ & $3.3 \pm 0.84$ & $0.14 \pm 0.63$ & $989.6 \pm 2.9$ \\
\hline & & Evening & 288 & $24.02 \pm 2.31$ & $83.8 \pm 4.72$ & $1.55 \pm 0.69$ & $0.0 \pm 0.02$ & $988.83 \pm 2.63$ \\
\hline & & Night & 319 & $20.8 \pm 2.34$ & $92.44 \pm 3.39$ & $1.65 \pm 0.95$ & $0.14 \pm 0.74$ & $989.09 \pm 2.89$ \\
\hline \multirow{8}{*}{ Male } & \multirow{4}{*}{ Spring } & Morning & 363 & $10.9 \pm 5.51$ & $80.54 \pm 8.85$ & $3.26 \pm 1.16$ & $0.12 \pm 0.69$ & $992.28 \pm 5.13$ \\
\hline & & Midday & 326 & $18.46 \pm 5.03$ & $54.44 \pm 13.4$ & $4.76 \pm 1.27$ & $0.09 \pm 0.45$ & $990.7 \pm 5.07$ \\
\hline & & Evening & 394 & $16.74 \pm 5.26$ & $60.01 \pm 12.72$ & $3.45 \pm 1.06$ & $0.18 \pm 1.13$ & $989.76 \pm 5.0$ \\
\hline & & Night & 395 & $11.49 \pm 5.98$ & $81.03 \pm 9.74$ & $2.72 \pm 1.22$ & $0.05 \pm 0.27$ & $990.47 \pm 5.17$ \\
\hline & \multirow{4}{*}{ Winter } & Morning & 349 & $4.66 \pm 4.84$ & $77.24 \pm 10.12$ & $3.43 \pm 1.25$ & $0.04 \pm 0.32$ & $995.83 \pm 5.67$ \\
\hline & & Midday & 309 & $12.04 \pm 4.84$ & $51.74 \pm 15.38$ & $4.71 \pm 1.32$ & $0.03 \pm 0.24$ & $994.18 \pm 5.74$ \\
\hline & & Evening & 339 & $8.75 \pm 4.83$ & $60.87 \pm 13.44$ & $2.93 \pm 1.0$ & $0.08 \pm 0.38$ & $993.72 \pm 5.58$ \\
\hline & & Night & 355 & $4.33 \pm 5.32$ & $78.21 \pm 9.43$ & $2.85 \pm 1.18$ & $0.07 \pm 0.53$ & $994.58 \pm 5.73$ \\
\hline
\end{tabular}

TABLE 4: Differences in mean ( \pm SE) movement relative to weather conditions. Weather conditions were classified as below normal (i.e., low) if $\leq 1$ SD from mean, above normal (i.e., high) if $\geq 1$ SD from the mean, and normal if SD was -1 to 1 . Values with the same letter did not differ at $\alpha=0.05$.

\begin{tabular}{|c|c|c|c|c|c|c|c|c|c|}
\hline Sex & Season & Time period & Weather variable & $F$ & $\mathrm{df}$ & $P$ & Low $(\leq-1 \mathrm{SD})$ & $\operatorname{Normal}(-1$ to 1$)$ & $\operatorname{High}(\geq 1 \mathrm{SD})$ \\
\hline \multirow{4}{*}{ Female } & \multirow{3}{*}{ Spring } & Midday & Temperature & 5.53 & 2,116 & .005 & 935 (143) A & 784 (129) AC & 568 (140) B \\
\hline & & \multirow{2}{*}{ Evening } & Relative humidity & 3.27 & 2,194 & .04 & 774 (136) A & 893 (124) AB & 999 (132) B \\
\hline & & & Temperature & 4.18 & 2,197 & .017 & 1068 (137) A & 846 (126) B & 877 (132) AB \\
\hline & Summer & Midday & Temperature & 3.88 & $2,95.9$ & .024 & $283(51) \mathrm{A}$ & $444(30) \mathrm{B}$ & 359 (64) AB \\
\hline \multirow{7}{*}{ Male } & \multirow{6}{*}{ Spring } & \multirow{3}{*}{ Morning } & Relative humidity & 3.40 & 2,186 & .035 & $1322(110) \mathrm{A}$ & $1021(55) \mathrm{B}$ & $1160(118) \mathrm{AB}$ \\
\hline & & & Temperature & 14.33 & 2,182 & $<.001$ & $1223(52) \mathrm{A}$ & $1200(52) \mathrm{A}$ & 610 (100) B \\
\hline & & & Wind speed & 3.45 & 2,160 & .034 & 1330 (104) A & $1061(56) \mathrm{A}$ & 942 (113) B \\
\hline & & Evening & Temperature & 5.97 & 2,248 & .003 & 1268 (98) A & $1070(70) \mathrm{AB}$ & 867 (96) B \\
\hline & & \multirow{2}{*}{ Night } & Precipitation & 6.70 & 1,279 & .01 & - & $519(50)$ & $844(133)$ \\
\hline & & & Temperature & 4.21 & 2,279 & .016 & $623(65) \mathrm{A}$ & $476(53) \mathrm{B}$ & 559 (64) $\mathrm{AB}$ \\
\hline & Winter & Evening & Relative humidity & 4.93 & 2,244 & .008 & 1256 (139) A & $940(121) \mathrm{B}$ & 987 (140) AB \\
\hline
\end{tabular}

Movements of females were more tortuous during peak parturition, likely because females used smaller areas more intensively [1].

Male deer also appear to change their daily movement patterns in response to breeding period (i.e., rut and postrut). Previous research has found that males will increase home range size during rut [8]. However, home range size between the rut and spring periods were similar for males on the NFWU [1]. Males appear to confine movements to previously established home ranges during the rut $[1,36]$ but may change their activity [37] or movements patterns within their home range based on fractal analyses [1]. We found males also changed their movement patterns by increasing movements during the rut compared to postrut. This finding corroborates the finding that male movements during rut were more linear, which may have resulted from increased movement distance. Therefore, confining movements to the home range may provide protection and security as evidenced by high annual home range fidelity $[36,38]$. Changing movement patterns within home ranges also may be because of responses for available resources (e.g., receptive females, forage, etc.), which will vary based on physiological state and condition and habitat quality.

Few studies have documented changes in diurnal and nocturnal movements across seasons. A study in Georgia revealed female deer moved twice as far during diurnal hours than nocturnal hours [16]. However, the D : N ratio reported was partially influenced by increased daylength. We found much lower D : $\mathrm{N}$ ratios because we accounted for number of hours within each time period. Therefore, researchers should consider using other possible movement parameters, such as movement rate, to account for discrepencies in daylength. 


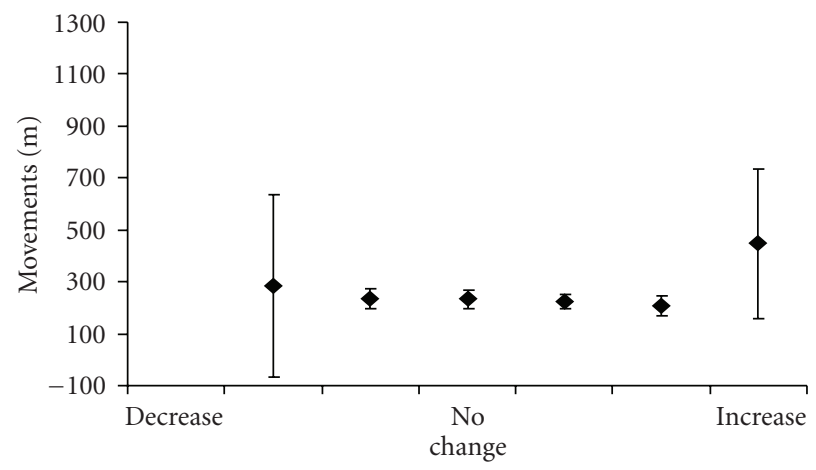

(a)

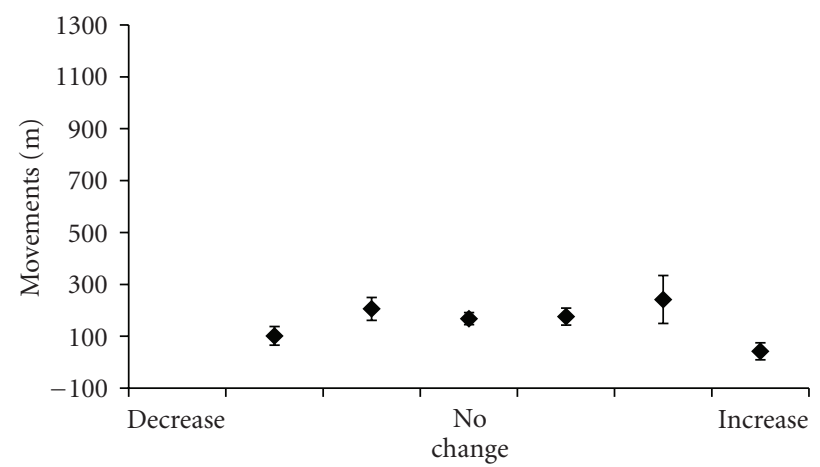

(c)

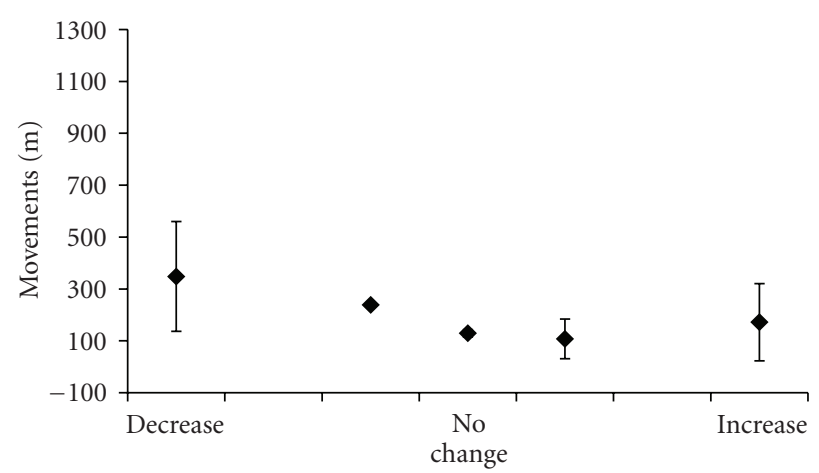

(e)

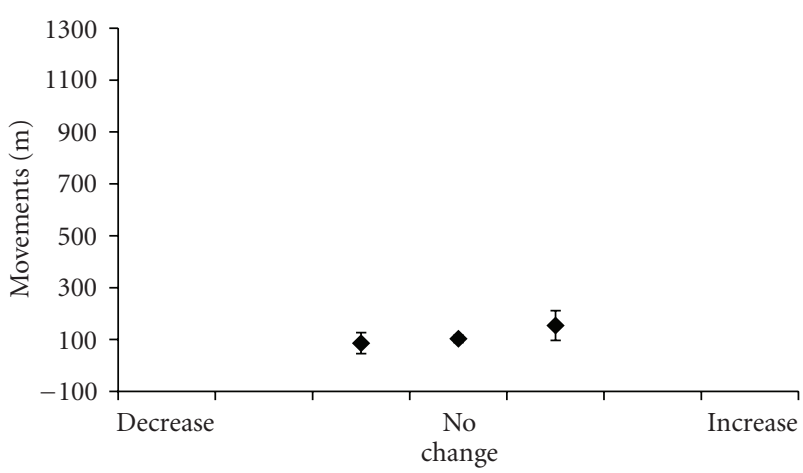

(g)

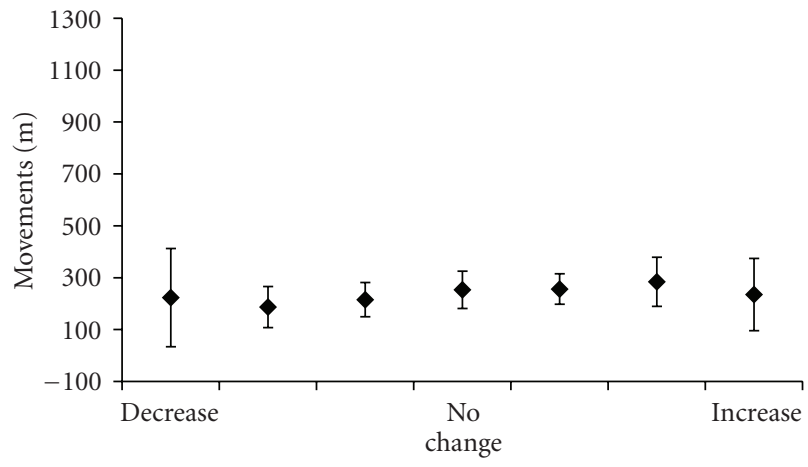

(b)

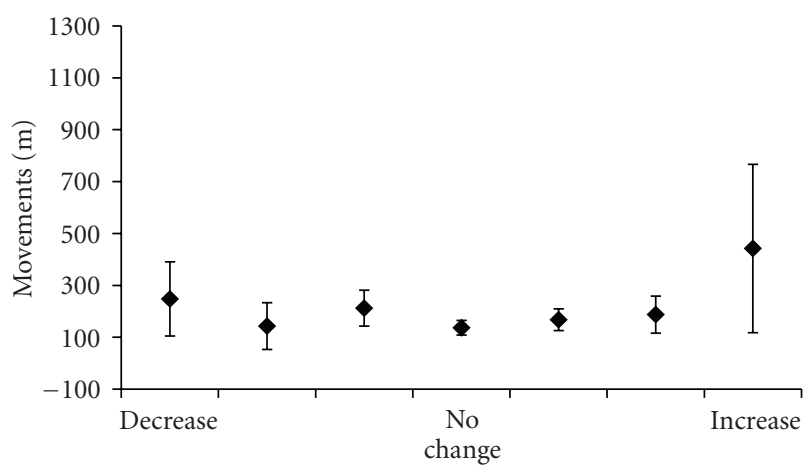

(d)

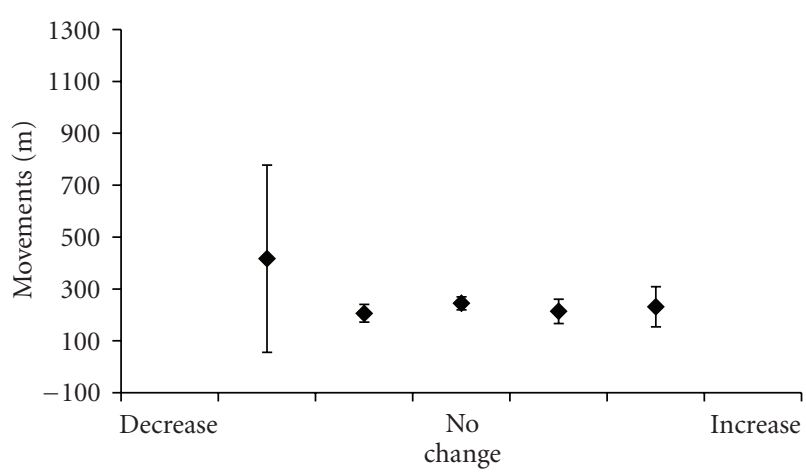

(f)

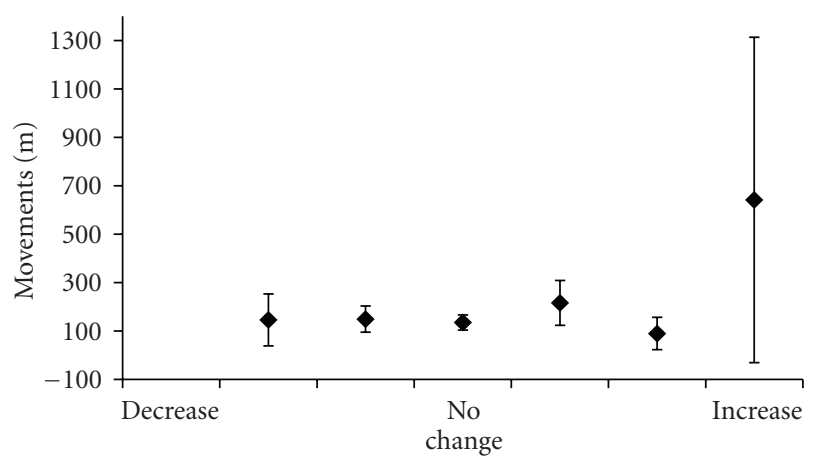

(h)

FIgUre 4: Continued. 


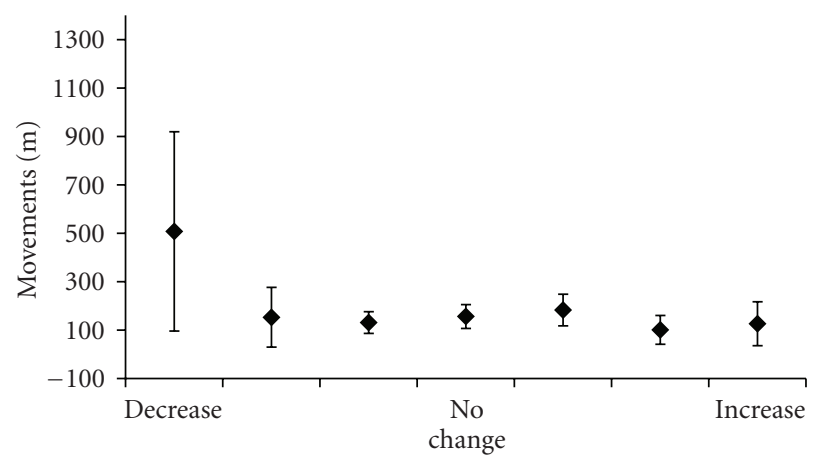

(i)

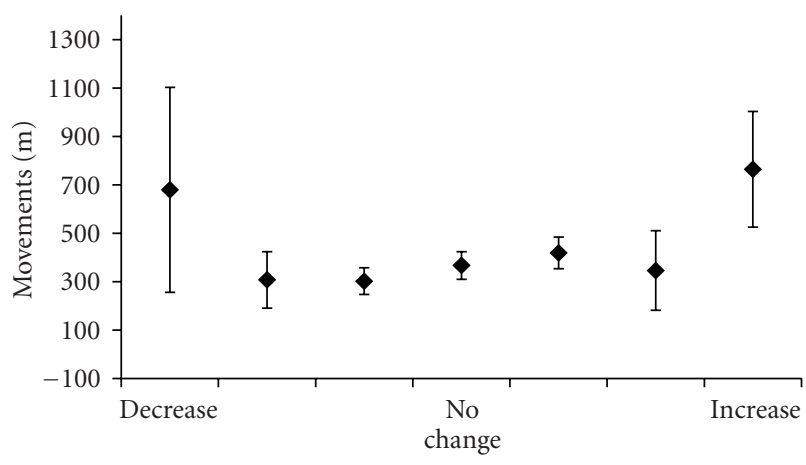

(j)

FIGURE 4: Plots of the effects of changes in weather within hour from day to day on hourly deer movements. Temperature influenced movements of females during spring at $\left.0100 \mathrm{hr}(\mathrm{a}) F_{5,368}=2.41, P=.036\right)$ and male during winter at 1300 hours $\left((\mathrm{b}) F_{6,227}=4.1, P<.001\right)$. Males movements were affected by relative humidity during spring at 0100 hours $\left((\mathrm{c}) F_{5,341}=2.56, P=.027\right)$ and 1300 hours $\left((\mathrm{d}) F_{6,244}=\right.$ $3.78, P=.001)$. Precipitation influenced female movements at 1300 hours during summer $\left((\mathrm{e}) F_{6,225}=3.35, P=.004\right)$. Pressure affected movements of females during spring at 0100 hours $\left((\mathrm{f}) F_{4,370}=2.58, P=.037\right)$ and summer at 0200 hours $\left((\mathrm{g}) F_{2,230}=3.12, P=.046\right)$ and male movements during winter at 1300 hours $\left((\mathrm{h}) F_{5,225}=4.82, P<.001\right)$. Male movements during winter were affected by wind speed at 1300 hours $\left((\mathrm{i}) F_{6,225}=3.35, P=.004\right)$ and 1800 hours $\left((\mathrm{j}) F_{6,303}=3.01, P=.007\right)$.

Female nocturnal movements during summer were greater than diurnal movements. However, in general, movements during summer were reduced compared to spring. Environmental temperature may influence activity rhythms in animals [39]; thus, changes in female movements during summer may be related to environmental conditions. However, our data indicated that environmental variation exerted minimal influence on deer movements at fine temporal scales within season. Therefore, changes in female movements from one season to the next may reflect changes in physiological state or acclimatization to seasonal conditions. Females appeared to adjust time budgets relative to movements. Movements generally were reduced during summer and increased at night, which may be a behavioral adaptation to reduce heat stress [39]. Because general movement patterns were changed during summer, weather had little influence on fine-scale temporal movements within this season.

We observed a large decrease in diurnal male movements (i.e., $\mathrm{D}: \mathrm{N}<1$ ) during winter compared to spring. Males in our study may have become more nocturnally active in winter because of hunting or the rut, both of which occurred during the winter season. Female deer were found to be less active during the hunting season during diurnal hours compared to nocturnal hours and the nonhunting season [40]. Males in our study may have responded in a similar fashion by decreasing daytime movements to avoid contact with hunters. Males also may have changed movement patterns because of rut. If females were more active at night during hunting season as found by Kilgo et al. [40], and since hunting season typically coincides with the breeding season and when females are in estrous on our study area, then it follows that male movement patterns during that time period may be similar to that of females because males are seeking or accompanying females. Unfortunately, we had no data for females during the rut, which makes examination of the 2 causes for changes in male movement patterns difficult.
The aforementioned explanations for nocturnal movement may outweight the costs of increases in metabolic rate during cold temperatures, which is related to thermoregulation and activity [41]. Activity, or movement in the present study, could incur a thermoregulatory penalty during cold weather that increases with increasing activity [41]. If this was true, deer should avoid moving at night during winter when temperatures are lowest to avoid increased metabolic rate. Temperature extremes in southern Oklahoma may not be cold enough for deer to be metabollically stressed to a point where compensation for increased metabolic rate could not be recovered, which may explain why deer were able to move more during this time. However, male deer voluntarilly reduce forage intake during rut, which may not allow them to meet metabolic requirements. Increased movements and decreased forage intake during rut may offer additional explanation for increased rut-related mortalities in males [42, 43].

Increasing moon phase generally results in decreased nocturnal activity or movements for many species (e.g., [44-48]. However, an observational study of mule deer (Odocoileus hemionus) occurrence at salt licks found that visitation to salt licks was highest during full moons [22]. Observational studies of white-tailed deer [12, 15], however, found that moon phase had no effect on number of deer sighted. We concur with the speculation of Zagata and Haugen [12] that the increase in deer sightings during full moons by Buss and Harbert [22] may have been because of increased observer ability to see during full moons and not an effect of moon phase itself. Observational studies are confounded by a number of factors such as visibility, vegetation types, time of day, and observer presence. Without the aid of night-vision optics, which were not available during earlier studies, deer would have been hard, if not impossible, to count during new moons. Because of limitations of observational studies, studies that remotely monitor animal movement or activity 
(e.g., activity collars and dataloggers; VHF telemetry; GPS collars) are preferred.

Previous studies have used variable-pulse activity sensors to monitor white-tailed deer [14, 49] and mule deer [24] activity patterns relative to moon phase. None of the aforementioned studies found an affect of moon phase on deer activity patterns. These findings are similar to ours in that moon phase had no influence on deer movement patterns.

Much conflicting evidence on the affects of weather on deer activity and movements exists in published literature $[8,14,16,49]$. Most studies have found minimal influence of weather on deer activity and movements except during certain seasons or environments. However, the 2 weather factors that consistently affected deer activity and movements, primarily in northern latitudes, were snow depth and temperature $[9,14,50-52]$. These factors are not as important to deer in southern latitudes, except for short periods.

Determining the full effects of weather on deer movements is often difficult because the two are often correlated on a seasonal basis [53] and movements may be correlated to predator activity, feeding [14] or breeding. However, our analysis approach allowed us to examine the influence of weather on deer movements within seasons and time periods removing much of the seasonal and daily variation in weather. In general, we found minimal evidence that weather was having an influence on deer movements. Relationships were weak and parameter estimates were small revealing little biological significance in changes in movement distance with changes in weather. Deviations from normal, seasonal weather conditions did not reveal consistent patterns for changes in movement. Interestingly, fine-scale temporal changes in weather over a 24 -hr period revealed movements during nonpeak movement periods (i.e., midday and night) were affected by some weather patterns whereas periods of normal deer movements (i.e., crepuscular movements) were not affected. Therefore, deer in the southern United States may not be as affected by weather as deer from northern latitudes, which experience more extreme weather conditions (e.g., snowfall, prolonged temperatures $<0^{\circ} \mathrm{C}$ ). Thus, deer tend to maintain normal, crepuscular movement patterns regardless of weather conditions.

Temperature was the only weather variable showing consistent effects on deer movements. Behavioral responses of deer may occur when environmental temperatures during summer are greatest or least during winter. Mule deer in an arid rangeland in Washington spent less time active and sought shade during hot weather $\geq 25^{\circ} \mathrm{C}$ [54]. However, female deer in this study moved greater distances during summer at times with normal to high temperatures and less when temperatures were coolest. Although female deer moved more during warmer temperatures of summer, movements in general were less than other seasons, which likely reduced heat stress from a general change in seasonal movement patterns or habitat type. Males during winter moved more when temperatures were lowest. Males may have moved more during winter evenings when temperatures were reduced in preparation of further drops in temperature during night. Therefore, males may have foraged more intensively or moved longer distances during the evening to reach favorable thermal habitats.

In conclusion, our study provided a thorough analysis of movement patterns of white-tailed deer using geospatial technologies that were not available in earlier studies. Therefore, our use of geospatial technologies and frequent interval between GPS fixes allowed us to model finescale temporal movements of deer and examine influences of short-term weather phenomena and moon phase on deer movements. Our short-time interval between GPS fixes ( 4 movements/hr or 2 movements/hr) likely captured realistic movement distances even though movement paths were tortuous [1]. Studies using relatively long intervals between locations may underestimate movement distances [55]. In addition to short intervals between GPS fixes, our study also had the advantage of continuously recording locations at 15-min intervals compared to previous studies which used "bursts" of telemetry locations to sample hourly or daily distance moved. Because our data were frequent and not limited by sampling intensity, we more accurately represented movement patterns across periods of interest.

\section{Acknowledgments}

The authors thank J. Holman for his numerous contributions to the project, all interns and volunteers that assisted during deer captures, and several anonymous reviewers for helpful comments on earlier drafts. Cooperative funding was provided by the Samuel Roberts Noble Foundation and the Mississippi State University Department of Wildlife, Fisheries and Aquaculture. This manuscript is contribution WF298 of the Mississippi State University Forest and Wildlife Research Center.

\section{References}

[1] S. L. Webb, S. K. Riffell, K. L. Gee, and S. Demarais, "Using fractal analyses to characterize movement paths of white-tailed deer and response to spatial scale," Journal of Mammalogy, vol. 90, no. 5, pp. 1210-1217, 2009.

[2] D. Pépin, C. Adrados, C. Mann, and G. Janeau, "Assessing real daily distance traveled by ungulates using differential GPS locations," Journal of Mammalogy, vol. 85, no. 4, pp. 774-780, 2004.

[3] J. J. Ozoga, L. J. Verme, and C. S. Bienz, "Parturition behavior and territoriality in white-tailed deer: impacts on neonatal mortality," Journal of Wildlife Management, vol. 46, pp. 1-11, 1982.

[4] M. R. Bertrand, A. J. Denicola, S. R. Beissinger, and R. K. Swihart, "Effects of parturition on home ranges and social affiliations of female white-tailed deer," Journal of Wildlife Management, vol. 60, no. 4, pp. 899-909, 1996.

[5] G. J. D’Angelo, C. E. Comer, J. C. Kilgo, C. D. Drennan, D. A. Osborn, and K. V. Miller, "Daily movements of female whitetailed deer relative to parturition and breeding," in Proceedings of the Annual Conference of Southeastern Association of Fish and Wildlife Agencies, vol. 58, pp. 292-301, 2004.

[6] C. M. Nixon, L. P. Hansen, P. A. Brewer, and J. E. Chelsvig, "Stability of white-tailed doe parturition ranges on a refuge in 
east-central Illinois," Canadian Journal of Zoology, vol. 70, no. 5, pp. 968-973, 1992.

[7] G. Schwede, H. Hendrichs, and W. McShea, "Social and spatial organization of female white-tailed deer, Odocoileus virginianus, during the fawning season," Animal Behaviour, vol. 45 , no. 5, pp. 1007-1017, 1993.

[8] R. L. Marchinton and D. H. Hirth, "Behavior," in White-Tailed Deer Ecology and Management, L. K. Halls, Ed., pp. 129-168, Stackpole Books, Harrisburg, Pa, USA, 1984.

[9] D. R. Progulske and D. C. Duerre, "Factors influencing spotlighting counts of deer," Journal of Wildlife Management, vol. 28, pp. 27-34, 1964.

[10] R. E. Hawkins and W. D. Klimstra, "Deer trapping correlated with weather factors," Transactions of the Illinois State Academy of Science, vol. 63, pp. 198-201, 1970.

[11] J. J. Ozoga and L. W Gysel, "Response of white-tailed deer to witner weather," Journal of Wildlife Management, vol. 36, pp. 892-896, 1972.

[12] M. D. Zagata and A. O. Haugen, "Influence of light and weather on observability of Iowa deer," Journal of Wildlife Management, vol. 38, pp. 220-228, 1974.

[13] D. R. McCullough, "Evaluation of night spotlighting as a deer study technique," Journal of Wildlife Management, vol. 46, pp. 963-973, 1982.

[14] P. Beier and D. R. McCullough, "Factors influencing whitetailed deer activity patterns and habitat use," Wildlife Monographs, vol. 109, pp. 1-15, 1990.

[15] E. D. Michael, "Activity patterns of white-tailed deer in south Texas," Texas Journal of Science, vol. 21, pp. 417-428, 1970.

[16] K. E. Kammermeyer and R. L. Marchinton, "Seasonal changes in circadian activity of white-tailed deer," Journal of Wildlife Management, vol. 41, pp. 315-317, 1977.

[17] R. A. Ockenfels and J. A. Bissonette, "Estimates of white-tailed deer activity levels in Oklahoma," Southeastern Association of Fish and Wildlife Agencies, vol. 36, pp. 445-453, 1982.

[18] R. A. Ockenfels and J. A. Bissonette, "Temperature-related responses in north-central oklahoma white-tailed deer," in Deer in the Southwest: A Symposium, P. R. Krausman and N. S. Smith, Eds., pp. 64-67, School of Natural Resources, University of Arizona, Tucson, Ariz, USA, 1984.

[19] J. Bello, S. Gallina, and M. Equihua, "Movements of the white-tailed deer and their relationship with precipitation in northeastern Mexico," Interciencia, vol. 29, no. 7, pp. 357-361, 2004.

[20] J. G. Teer, "The white-tailed deer: natural history and management," in The Society for Range Management, P. R. Krausman, Ed., pp. 193-210, Rangeland wildlife, Denver, Colo, USA, 1996.

[21] C. J. Alsheimer, Hunting Whitetails by the Moon, Krause Publications, Iola, Wis, USA, 1999.

[22] I. O. Buss and F. H. Harbert, "Relation of moon phases to the occurrence of mule deer at a Washington salt lick," Journal of Mammalogy, vol. 31, no. 4, pp. 426-429, 1950.

[23] K. E. Kammermeyer, Movement ecology of white-tailed deer in relation to a refuge and a hunted area, M.S. thesis, University of Georgia, Athens, Ga, USA, 1975.

[24] R. C. Kufeld, D. C. Bowden, and D. L. Schrupp, "Habitat selection and activity patterns of female mule deer in the Front Range, Colorado," Journal of Range Management, vol. 41, pp. 515-522, 1988.

[25] T. D. Reynolds and J. W. Laundré, "Time intervals for estimating pronghorn and coyote home ranges and daily movements," Journal of Wildlife Management, vol. 54, no. 2, pp. 316-322, 1990.
[26] S. L. Webb, K. L. Gee, S. Demarais, B. K. Strickland, and R. W. DeYoung, "Efficacy of a 15-strand high-tensile electric fence to control white-tailed deer movements," Wildlife Biology in Practice, vol. 5, no. 1, pp. 45-57, 2009.

[27] K. L. Gee, M. D. Porter, S. Demarais, F. C. Bryant, and G. V. Vreede, White-Tailed Deer: Their Foods and Management in the Cross Timbers, Samuel Roberts Noble Foundation, Ardmore, Okla, USA, 2nd edition, 1994.

[28] National Climatic Data Center, Climatological Data Annual Summary: Oklahoma, vol. 108-114, Department of Commerce, National Oceanic and Atmospheric Administration, Asheville, NC, USA, 1999-2005.

[29] C. W. Ramsey, "A drop-net deer trap," Journal of Wildlife Management, vol. 32, pp. 187-190, 1968.

[30] K. L. Gee, J. H. Holman, and S. Demarais, "A man-power efficient drop-net system for capturing white-tailed deer," in Proceeding of the Abstracts of the Annual Southeast Deer Study Group, 1999, abstract no. 22:31.

[31] SAS Institute, SAS OnlineDoc, Version 9.1.3., SAS Institute, Cary, NC, USA, 2003.

[32] R. C. Littell, G. A. Milliken, W. W. Stroup, R. D. Wolfinger, and O. Schabenberger, SAS ${ }^{\circledR}$ for Mixed Models, SAS Institute, Cary, NC, USA, 2nd edition, 2006.

[33] K. P. Burnham and D. R. Anderson, Model Selection and Inference: A Practical Information-Theoretic Approach, Springer, New York, NY, USA, 2nd edition, 2002.

[34] J. C. Kurz and R. L. Marchinton, "Radiotelemetry studies of feral hogs in south Carolina," Journal of Wildlife Management, vol. 36, pp. 1240-1248, 1972.

[35] M. G. Kenward and J. H. Roger, "Small sample inference for fixed effects from restricted maximum likelihood," Biometrics, vol. 53, no. 3, pp. 983-997, 1997.

[36] M. W. Hellickson, T. A. Campbell, K. V. Miller, R. L. Marchinton, and C. A. DeYoung, "Seasonal ranges and site fidelity of adult male white-tailed deer (Odocoileus virginianus) in southern Texas," Southwestern Naturalist, vol. 53, no. 1, pp. 18, 2008.

[37] M. W. Hellickson, Age-specific physical characteristics, activity, and behavior patterns of male white-tailed deer in southern Texas, Ph.D. dissertation, University of Georgia, Athens, Ga, USA, 2002.

[38] S. L. Webb, D. G. Hewitt, and M. W. Hellickson, "Scale of management for mature male white-tailed deer as influenced by home range and movements," Journal of Wildlife Management, vol. 71, no. 5, pp. 1507-1512, 2007.

[39] D. Randall, W. Burggren, and K. French, Eckert Animal Physiology: Mechanisms and Adaptations, W. H. Freeman, New York, NY, USA, 2002.

[40] J. C. Kilgo, R. F. Labisky, and D. E. Fritzen, "Influences of hunting on the behavior of white-tailed deer: implications for conservation of the Florida panther," Conservation Biology, vol. 12, no. 6, pp. 1359-1364, 1998.

[41] C. C. Gates and R. J. Hudson, "Effects of posture and activity on metabolic responses of wapiti to cold," Journal of Wildlife Management, vol. 43, pp. 564-567, 1979.

[42] S. L. Webb, D. G. Hewitt, and M. W. Hellickson, "Survival and cause-specific mortality of mature male white-tailed deer," Journal of Wildlife Management, vol. 71, no. 2, pp. 555-558, 2007.

[43] S. S. Ditchkoff, E. R. Welch Jr., R. L. Lochmiller, R. E. Masters, and W. R. Starry, "Age-specific causes of mortality among male white-tailed deer support mate-competition theory," Journal of Wildlife Management, vol. 65, no. 3, pp. 552-559, 2001. 
[44] M. A. Bowers, "Seed removal experiments on desert rodents: the microhabitat by moonlight effect," Journal of Mammalogy, vol. 69, pp. 201-204, 1988.

[45] B. S. Gilbert and S. Boutin, "Effect of moonlight on winter activity of snowshoe hares," Arctic \& Alpine Research, vol. 23, no. 1, pp. 61-65, 1991.

[46] W. J. Cresswell and S. Harris, "The effects of weather conditions on the movement and activity of badgers (Meles meles) in a suburban environment," Journal of Zoology, vol. 216, pp. 187-194, 1988.

[47] D. Julien-Laferrière, "The influence of moonlight on activity of woolly opossums (Caluromys philander)," Journal of Mammalogy, vol. 78, no. 1, pp. 251-255, 1997.

[48] H. G. Erkert, "Lighting requirements of nocturnal primates in captivity: a chronobiological approach," Zoo Biology, vol. 8, pp. 179-191, 1989.

[49] M. W. Hellickson, K. V. Miller, R. L. Marchinton, C. A. DeYoung, and C. J. Zabransky, "Weather affects on activity rates of male white-tailed deer in southern Texas," in Proceedings of the Annual Southeast Deer Study Group, pp. 30-44, 2007.

[50] C. M. Loveless, "Some relationships between wintering mule deer and the physical environment," in Transactions of the North American Wildlife and Natural Resources Conference, vol. 29, pp. 415-431, 1964.

[51] O. J. Rongstad and J. R. Tester, "Movements and habitat use of white-tailed deer in Minnesota," Journal of Wildlife Management, vol. 33, pp. 366-379, 1969.

[52] A. N. Moen, "Energy conservation by white-tailed deer in the winter," Ecology, vol. 57, pp. 192-198, 1976.

[53] G. C. White and R. A. Garrott, Analysis of Wildlife RadioTracking Data, Academic Press, San Diego, Calif, USA, 1990.

[54] G. A. Sargeant, L. E. Eberhardt, and J. M. Peek, "Thermoregulation by mule deer (Odocoileus hemionus) in arid rangelands of southcentral Washington," Journal of Mammalogy, vol. 75, no. 2, pp. 536-544, 1994.

[55] K. J. Mills, B. R. Patterson, and D. L. Murray, "Effects of variable sampling frequencies on GPS transmitter efficiency and estimated wolf home range size and movement distance," Wildlife Society Bulletin, vol. 34, no. 5, pp. 1463-1469, 2006. 

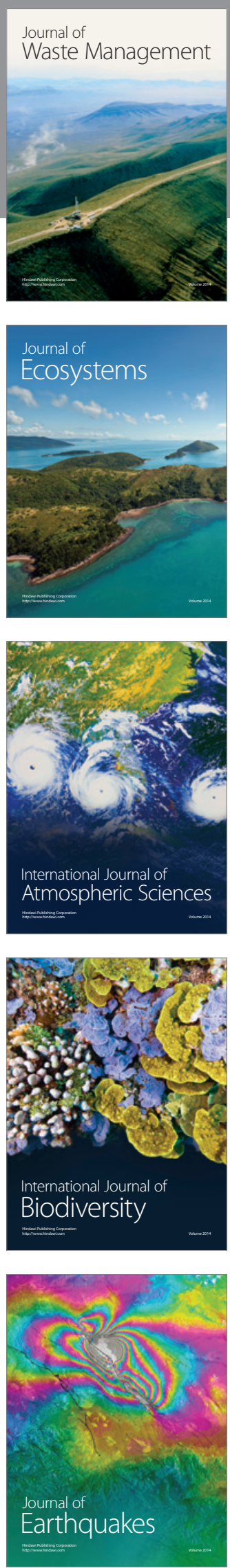
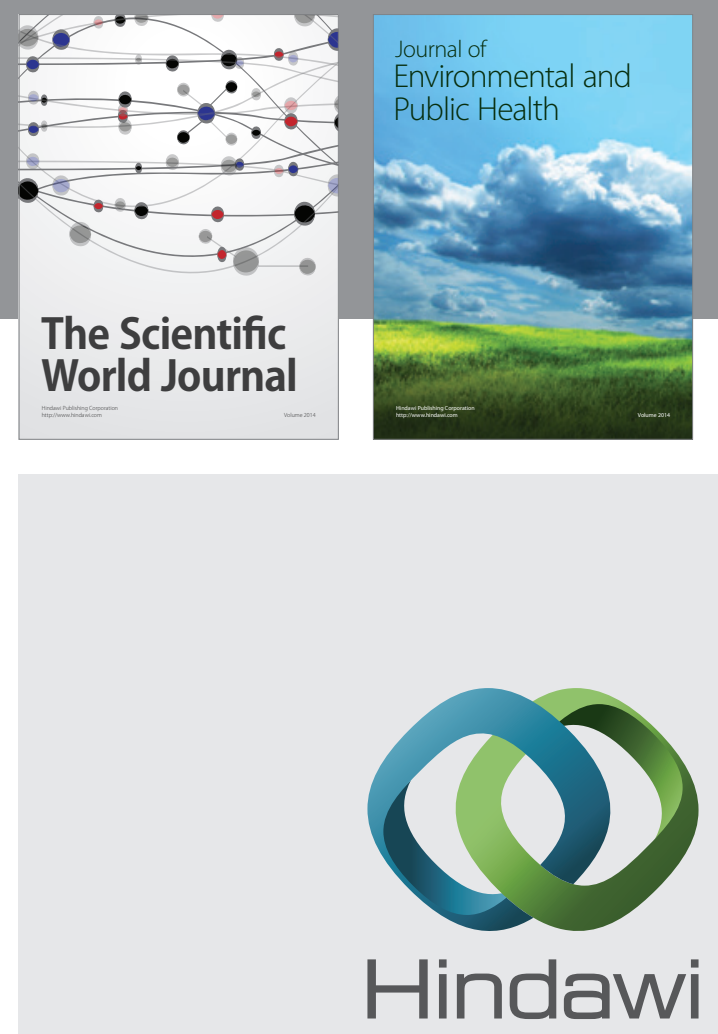

Submit your manuscripts at

http://www.hindawi.com
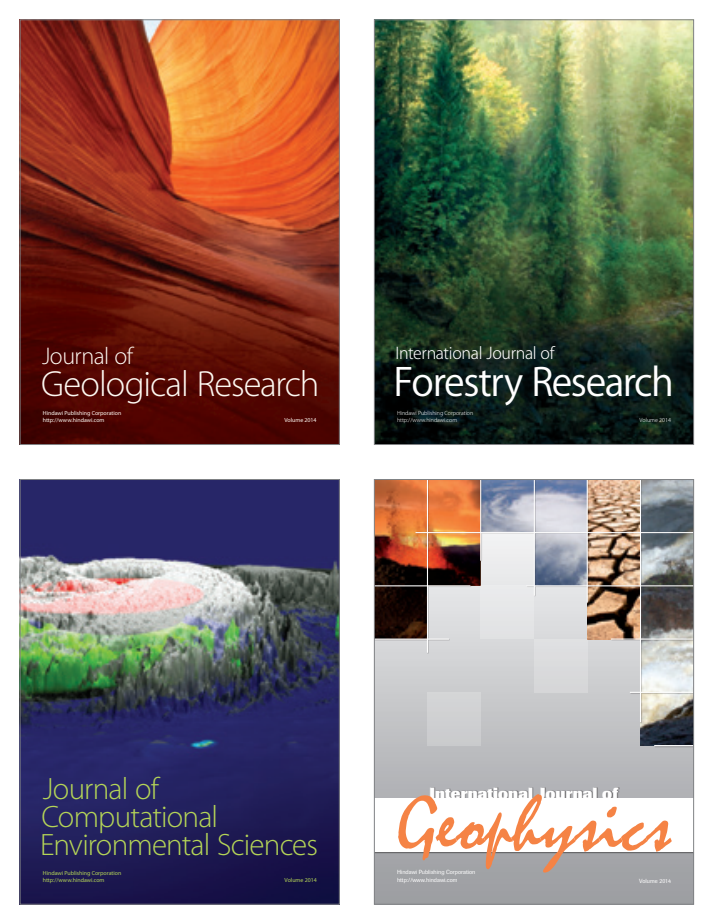
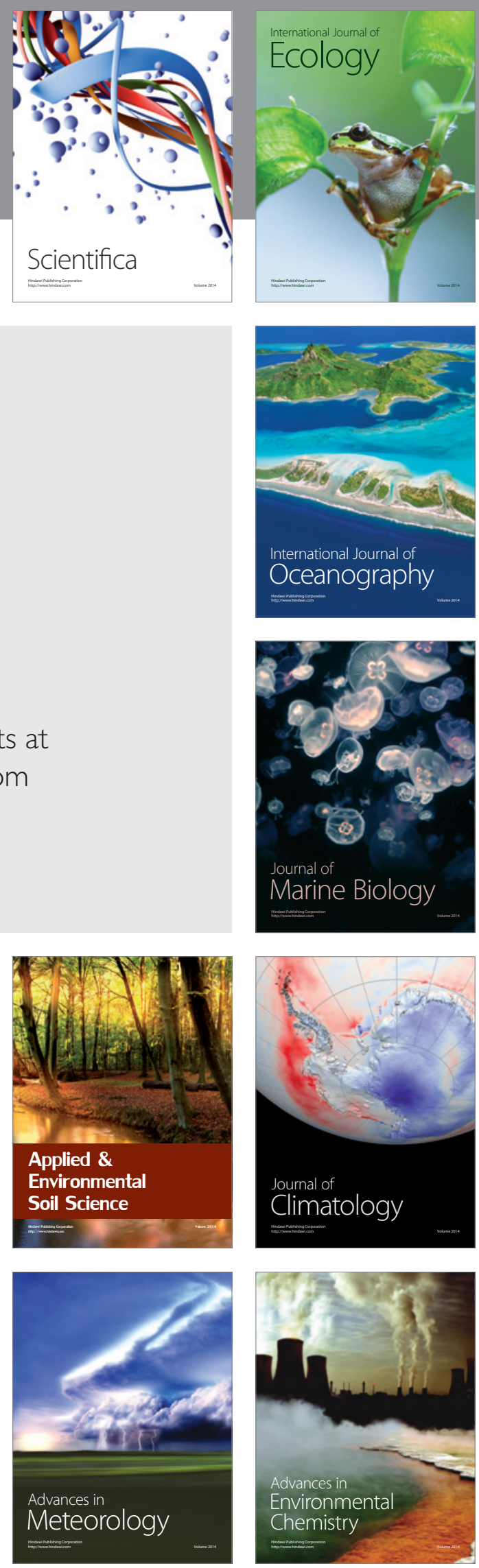